\title{
Mitigation of power oscillations using hybrid DE-PSO optimization-based SSSC damping controller
}

\author{
Soudamini Behera ${ }^{1,4}$, Ajit Kumar Barisal $^{2^{*}}$ (E) Nirmalya Dhal ${ }^{3}$ and Deepak Kumar Lal ${ }^{1}$
}

*Correspondence:
a_barisal@rediffmail.com
${ }^{2}$ Department of Electrical
Engineering, College
of Engineering
and Technology,
Bhubaneswar, Odisha
751029 , India
Full list of author information
is available at the end of the
article

${ }^{*}$ Correspondence:

a_barisal@rediffmail.com

Engineering, College

of Engineering

and Technology,

Bhubaneswar, Odisha

Full list of author information

article

\begin{abstract}
This paper presents an optimal design of a static synchronous series compensator (SSSC)-based controller for damping of low-frequency oscillations in multi-machine power systems. The proposed controller design problem is formulated to the optimization problem. The tuning of controller parameters can be obtained by employing a new hybrid differential evolution and particle swarm optimization (hDE-PSO) algorithm. To justify the effectiveness of the proposed SSSC-based damping controller, three-machine and four-machine power systems have been considered. The hDE-PSO algorithm outperforms in the damping of oscillations over DE and PSO algorithms. Various simulation results are presented and compared for different load disturbances like three-phase fault, load rejection and tripping of one parallel transmission line. The simulation results ensure the robustness of the proposed controller.
\end{abstract}

Keywords: Differential evolution algorithm, Particle swarm optimization, Power system stability, Static synchronous series compensator

\section{Introduction}

Due to rapid industrialization and urbanization, the load demand increases day by day. In order to meet the growing load demand, the level of power transmission increases largely through existing interconnections. These interconnections are becoming weak, and inadequate load characteristics added to the problem cause spontaneous low-frequency $(1-3 \mathrm{~Hz})$ oscillations. To preserve the synchronism against these oscillations, adequate damping is required [1]. Power system stabilizer (PSS) is the most popular device to damp out these oscillations [2]. However, traditional PSS cannot damp out all oscillations except local oscillation mode. In addition, PSSs cannot provide sufficient damping for oscillations resulting from severe faults such as three-phase short-circuit fault.

During the last two decades, invent of power electronics technology-based flexible AC transmission system (FACTS) acts as a promising application toward power system stability [3]. FACTS controllers have the potential to significantly improve the stability margin. FACTS controllers can influence transmission system voltages, currents and impedance and/or phase angles rapidly. These typical features of FACTS controllers can be used to improve stability of a power system [4]. FACTS controllers can control the network condition in a very efficient manner. FACTS controllers enhance utilization of

(c) The Author(s) 2019. This article is distributed under the terms of the Creative Commons Attribution 4.0 International License (http://creativecommons.org/licenses/by/4.0/), which permits unrestricted use, distribution, and reproduction in any medium, provided you give appropriate credit to the original author(s) and the source, provide a link to the Creative Commons license, and indicate if changes were made. 
current networks up to their thermal loading capacity instead of constructing new transmission lines. Recently, series FACTS controllers have shown superior and competitive features to improve power oscillation damping (POD) and frequency oscillation damping (FOD) [5]. Static synchronous series compensator (SSSC) is one of the important members of FACTS family. The SSSC can effectively control the power flow in a line by changing its reactance characteristic from capacitive to inductive and independent of the magnitude of the line current $[6,7]$ and also immune to classical network series resonances. An ancillary damping controller is designed for SSSC to damp out oscillations [8]. The extensive study of power oscillation damping, stability enhancement and frequency stabilization is reported in [9]. The impact of degree of compensation and mode of operation of SSSC on transient stability and small disturbance is also studied in $[10,11]$. Most of the reported results based on small disturbance analysis use a linear model of the system. However, linear methods fail to address satisfactorily the dynamics behavior of power systems under major disturbances. The designed controllers that perform satisfactorily at small signal conditions may not assure desirable performance during large disturbances.

In this work, the nonlinear model of multi-machine power system with SSSC controller is developed in MATLAB/Simulink environment. A conventional lead-lag controller structure is implemented because of its simplicity, reliability and less design process [12]. The selection of suitable control input for the controller is paramount importance in achieving desirable performance. The two common input signals are local signal and remote signal. In the case of local signal active power, reactive power, line current magnitude or line voltage magnitude can be used as a controlling input. But, line active power and line current are mostly used as local input signals in the literature. The generator rotor angle and speed deviation are considered as remote signals. Remote signal (rotor speed deviation) is found to be better than the local signal as an input signal to SSSC controller for damping of inter-area mode of oscillations [13]. In this work, generator rotor speed deviation is used as a controlling input to the proposed controller.

Tuning of controller parameters is a difficult task. A number of conventional methods are being used, but those are prone to be trapped by local minima. In recent years, evolutionary and swarm intelligence-based algorithms are becoming a more popular and effective tool in solving complex nonlinear and non-differentiable problems. The differential evolution (DE) algorithm is a population-based evolutionary algorithm [14] widely used in a variety of fields due to its one-to-one completion and hundred percent success rate. Particle swarm optimization (PSO) is a trusted swarm intelligence-based stochastic algorithm [15]. In this paper, hybridization of DE and PSO is done to find out optimal values of controller parameters [16]. A time delay of $15 \mathrm{~ms}$ for sensor and $50 \mathrm{~ms}$ for signal transmission is considered in this work. To show the effectiveness and robustness of the proposed hDE-PSO approach, simulation results are compared with DE and PSObased controller under different disturbances.

\section{System model}

To verify the performance of the proposed approach, a multi-machine power system with SSSC is considered as used in [13]. Figure 1 shows a power system with SSSC which consists of three generators divided into two areas connected through tie line. Area 1 


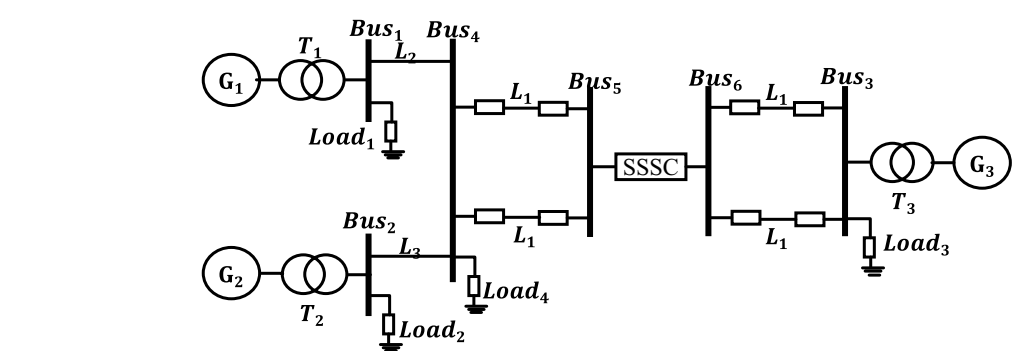

Fig. 1 Three-machine power system with SSSC

consists of two generators $G_{1}$ and $G_{2}$. The area 2 has one generator $G_{3} . T_{1}, T_{2}$ and $T_{3}$ are represented as three transformers. The SSSC is connected in between area 1 and 2 to damp out the system oscillations. A SSSC is connected in series with the transmission line and can inject ac voltage at the desired frequency with controllable amplitude and phase angle. Hence, the injected voltage by the SSSC acts as a virtual compensation of the line reactance. The voltage source converter (VSC) uses IGBT-based PWM inverters to produce ac voltages from a dc voltage source. The VSC is connected to the line through a coupling transformer. A capacitor link is used as a dc source and draws a small amount of active power from the line for its charging and to meet transformer and VSC losses. All the parameter ratings of the SSSC and other power system components are provided in [16].

\section{Proposed approach}

\section{Structure of SSSC-based damping controller}

A commonly used lead-lag structured controller consists of a delay block $(D)$, a gain block $\left(K_{s}\right)$, a signal washout block and a two-stage lead-lag block. The delay block depends on the type of input signal fed to the controller. For local signal only, senor delay is considered. But, for remote signal, sensor as well as signal transmission delays are considered. The signal washout filter is a high-pass filter that rejects steady-state inputs and passes transient inputs. The washout block with the time constant $T_{\mathrm{w}}$ is high enough to allow signals associated with oscillations in the input signal to pass unchanged. From the viewpoint of the washout function, the value of $T_{\mathrm{w}}$ is not critical and may be in the range of 1-20 s [1,13]. Most of the previous literatures have considered the value of $T_{\mathrm{w}}$ as $10 \mathrm{~s}$. In view of the above, the value of $T_{\mathrm{w}}$ is taken as $10 \mathrm{~s}$ in the present work. A two-stage lead-lag compensator (time constants $T_{1 s}, T_{2 s}, T_{3 s}$ and $T_{4 s}$ ) provides proper phase compensation between the input and output signals. The values of $K_{s}, T_{1 s}, T_{2 s}, T_{3 s}$ and $T_{4 s}$ are obtained using the proposed optimization algorithm.

\section{Problem formulation}

The oscillations in power system can be seen as deviations in rotor speed, power angle or tie-line power. Minimization of any one of the above parameters can be taken as an objective function of the problem. Here, integral time absolute error (ITAE) of the speed deviations of local and inter-area mode of oscillations has been taken as an objective function. The objective function $J$ is defined as: 


$$
J=\int_{t=0}^{t=t_{\mathrm{sim}}}\left(\left|\omega_{1}-\omega_{2}\right|+\left|\omega_{1}-\omega_{3}\right|\right) \cdot t \cdot \mathrm{d} t
$$

where $\omega_{1}, \omega_{2}$ and $\omega_{3}$ are the speed deviations of the generators $G_{1}, G_{2}$ and $G_{3}$, respectively; $t_{\text {sim }}$ is the simulation time range.

\section{Algorithm used}

In this work, hybrid DE-PSO [16] optimization algorithm is used to tune the controller parameters (i.e., time constants $T 1, T 2, T 3$ and $T 4$ ). The phase compensation blocks (time constants $T 1, T 2, T 3$ and $T 4$ ) provide the appropriate phase lead characteristics to compensate for the phase lag between the input and output signals, which are responsible for the series injected voltage to damp out oscillations. The value of the objective function is an integral of time multiplied absolute error (ITAE) of the speed deviations of local and inter-area mode of oscillations. Thus, the time constants $T 1, T 2, T 3$ and $T 4$ are related to the objective function. hDE-PSO starts with the usual DE, and then, PSO is incorporated to reach the optimal solution. DE operators like selection, crossover and mutation are applied to the PSO. Thus, the diversity in population increases and makes the PSO to escape local optima. However, the main disadvantage in DE is the lack of memory. PSO combines individual through local best $\left(P_{\text {best }}\right)$ and global best $\left(P_{\text {gbest }}\right)$. To take the advantages of both the algorithms, that is, to maintain the diversity and to add memory in population, hDE-PSO algorithm is associated with the present work. Different computational steps adopted in this hDE-PSO [16] algorithm are as follows:

Step 1: Initialize a random population of size $[N P \times D]$

where row represents the population $N P$ and column represents the dimension $D$. Step 2: Initialize the velocity randomly for each particle to be used in PSO algorithm. Step 3: DE operation

(1) Generate the donor vector $V_{i}$ from parent vectors

$$
V_{i}=X_{i, r_{1}}+F \times\left(X_{i, r_{2}}-X_{i, r_{3}}\right),
$$

where $r_{1}, r_{2}$ and $r_{3}$ are three distinct integers chosen between 1 and NP. $F$ is the scaling factor.

Calculate the offspring vector $U_{i}$ to perform crossover operation

$$
U_{i}=V_{i}, \quad \text { if } \operatorname{rand}(0,1) \leq \mathrm{CR} \text { or } j=j_{\text {rand }}
$$

$U_{i}=X_{i}$, otherwise, where $\mathrm{CR}$ is the crossover rate.

Choose the target vector to be used in the selection process as in Eq. (4):

$$
X_{i}=\left\{\begin{array}{l}
U_{i}, \text { if } f\left(U_{i}\right) \leq f\left(X_{i}\right) \\
X_{i}, \text { otherwise }
\end{array}\right.
$$

where $f=J$ is the function to be minimized. 
Table 1 Optimized controller parameters

\begin{tabular}{|c|c|c|c|c|c|c|}
\hline Techniques & $K_{s}$ & $T_{1 \mathrm{~s}}$ & $T_{2 s}$ & $T_{3 s}$ & $T_{4 \mathrm{~s}}$ & ITAE $\times 10^{-4}$ \\
\hline $\mathrm{DE}$ & 230.4453 & 0.6653 & 0.7726 & 0.3567 & 0.6654 & 3.69 \\
\hline PSO & 223.2655 & 0.6463 & 0.5212 & 0.3723 & 0.9371 & 4.21 \\
\hline hDE-PSO & 420.5432 & 0.3545 & 0.4301 & 0.5722 & 0.7008 & 2.67 \\
\hline
\end{tabular}

(2) Identify the local best $\left(P_{\text {best }}\right)$ and the global best $\left(P_{\text {gbest }}\right)$.

Step 4: PSO operation

(1) Take $X_{i}$ as the initial population obtained in step (3) of DE operation.

(2) Update the velocity of each particle in Eq. (5):

$$
v_{i}^{i+1}=w v_{i}^{i}+c_{1} \operatorname{rand}_{1}\left(p_{i, \text { best }}^{k}-x_{i}^{k}\right)+c_{2} \operatorname{rand}_{2}\left(p_{i, \text { gbest }}^{k}-x_{i}^{k}\right),
$$

where $c_{1}$ and $c_{2}$ are acceleration coefficients. $w$ is the inertia weight whose value linearly decreases from 0.9 to 0.4 with iteration. rand $_{1}$ and rand $_{2}$ are two random numbers in the range $[0,1]$.

(3) Update the swarm position using Eq. (6):

$$
X_{i, \text { new }}=X_{i}+V_{i} .
$$

(4) Evaluate the fitness of the objective function.

(5) Select the best solutions for the next iteration by comparing the fitness using Eq. (7):

$$
X_{i}^{G+1}=\left\{\begin{array}{ll}
X_{i, \text { new }}, & \text { if } f\left(X_{i, \text { new }}\right) \leq f\left(X_{i}\right) \\
X_{i}, & \text { otherwise }
\end{array} .\right.
$$

Step 5: Increase the generation count.

Step 6: Repeat steps 3-5 until stopping criteria are met.

\section{Simulation results and discussion}

The simulation study has been implemented in MATLAB 7.10.0.499 (R2010a) environment on a $2.30 \mathrm{GHz}$, Intel Core-i5 processor with 4 GB RAM PC. The proposed hDE-PSO algorithm has been applied to the multi-area power systems for frequency oscillation damping when subjected to different disturbances. The SPS toolbox is used for all simulations and SSSC-based damping controller design. The SPS is a MATLABbased modern design tool that allows the user to rapidly and easily build models to simulate power systems using the Simulink environment. The optimized values of the controller parameters are given in Table 1. The load flow and machine initialization parameters are given in Table 2. 
Table 2 Load flow and machine initialization

\begin{tabular}{|c|c|c|c|}
\hline Machine name & Generator $1 \mathrm{M} 1$ & Generator $2 \mathrm{M} 2$ & Generator $3 \mathrm{M} 3$ \\
\hline Nominal values & 2100 MVA 13.8 kV rms & $2100 \mathrm{MVA} 13.8 \mathrm{kV}$ rms & $4200 \mathrm{MVA} 13.8 \mathrm{kV}$ rms \\
\hline Bus type & $P$ and $V$ generator & $\mathrm{P}$ and $\mathrm{V}$ generator & Swing bus \\
\hline Uan phase & $56.92^{\circ}$ & $58.35^{\circ}$ & $0.00^{\circ}$ \\
\hline Uab & $13,800 \mathrm{Vrms}[1 \mathrm{pu}] 86.92^{\circ}$ & $13,800 \mathrm{Vrms}[1 \mathrm{pu}] 88.35^{\circ}$ & $13,938 \mathrm{Vrms}[1.01 \mathrm{pu}] 30.00^{\circ}$ \\
\hline Ubc & 13,800 Vrms $[1 \mathrm{pu}]-33.08^{\circ}$ & 13,800 Vrms $[1 \mathrm{pu}]-31.65^{\circ}$ & 13,938 Vrms $[1.01 \mathrm{pu}]-90.00^{\circ}$ \\
\hline Uca & 13,800 Vrms $[1 \mathrm{pu}]-153.08^{\circ}$ & 13,800 Vrms $[1 \mathrm{pu}]-151.65^{\circ}$ & $13,938 \mathrm{Vrms}[1.01 \mathrm{pu}] 150.00^{\circ}$ \\
\hline la & $\begin{array}{l}\text { 82,267 Arms [0.9364 pu] } \\
32.19^{\circ}\end{array}$ & $\begin{array}{l}\text { 57,751 Arms }[0.6573 \mathrm{pu}] \\
36.37^{\circ}\end{array}$ & $\begin{array}{l}2.0522 \mathrm{e}+005 \operatorname{Arms}[1.168 \mathrm{pu}] \\
\quad-38.67^{\circ}\end{array}$ \\
\hline $\mathrm{lb}$ & $\begin{array}{l}82,267 \text { Arms [0.9364 pu] } \\
-87.81^{\circ}\end{array}$ & $\begin{array}{l}\text { 57,751 Arms [0.6573 pu] } \\
-83.63^{\circ}\end{array}$ & $\begin{array}{l}2.0522 \mathrm{e}+005 \text { Arms [1.168 pu] } \\
-158.66^{\circ}\end{array}$ \\
\hline IC & $\begin{array}{l}82,267 \text { Arms }[0.9364 \mathrm{pu}] \\
152.19^{\circ}\end{array}$ & $\begin{array}{l}57,751 \text { Arms [0.6573 pu] } \\
\quad 156.37^{\circ}\end{array}$ & $\begin{array}{l}2.0522 \mathrm{e}+005 \text { Arms [1.168 pu] } \\
81.33^{\circ}\end{array}$ \\
\hline P & $1.786 \mathrm{e}+009 \mathrm{~W}[0.8505 \mathrm{pu}]$ & $1.28 \mathrm{e}+009 \mathrm{~W}[0.6095 \mathrm{pu}]$ & $3.8684 \mathrm{e}+009 \mathrm{~W}[0.9211 \mathrm{pu}]$ \\
\hline Q & $8.2261 \mathrm{e}+008 \operatorname{Vars}[0.3917 \mathrm{pu}]$ & $1.28 \mathrm{e}+009 \mathrm{~W}[0.6095 \mathrm{pu}]$ & $3.0953 \mathrm{e}+009$ Vars $[0.737 \mathrm{pu}]$ \\
\hline Pmec & $1.7913 e+009 \mathrm{~W}[0.853 \mathrm{pu}]$ & $1.2826 \mathrm{e}+009 \mathrm{~W}[0.6108 \mathrm{pu}]$ & $3.8848 \mathrm{e}+009 \mathrm{~W}[0.925 \mathrm{pu}]$ \\
\hline Torque & $1.5205 \mathrm{e}+008 \mathrm{~N} \mathrm{~m}[0.853 \mathrm{pu}]$ & $1.0887 e+008$ N m [0.6108] & $3.2975 \mathrm{e}+008 \mathrm{~N} \mathrm{~m}[0.925 \mathrm{pu}]$ \\
\hline$V f$ & $1.7892 \mathrm{pu}$ & 1.4793 pu & $2.2318 \mathrm{pu}$ \\
\hline
\end{tabular}

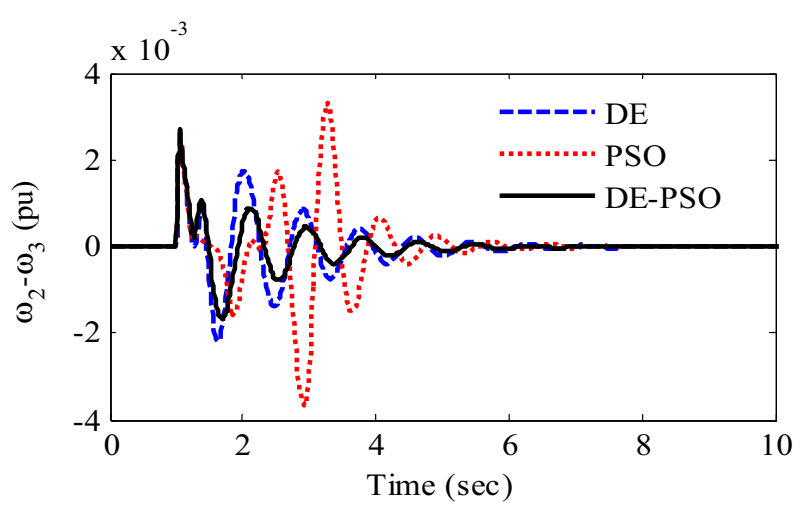

Fig. 2 Inter-area mode oscillation

Case 1 Three-phase fault: A three-cycle three-phase fault is applied at bus-6, at $t=1 \mathrm{~s}$. The fault is cleared by the tripping of the faulted line. The line is reclosed after three cycles, and the original system is restored. The system response under this severe fault is shown in Figs. 2 and 3. Figure 2 shows the inter-area mode of oscillation, and Fig. 3 shows the local mode of oscillation.

In those figures, the response with DE-based controller is shown with dashed line (with legend DE); the response with PSO-based controller is shown with dotted line (with legend PSO); and the response with hDE-PSO-based controller is shown with solid line (with legend DE-PSO). From these figures, it is clear that the proposed controller gives a better response in terms of damping and settling time. Figures 4 and 5 show the responses of inter-area and local mode of oscillation, respectively, for local 


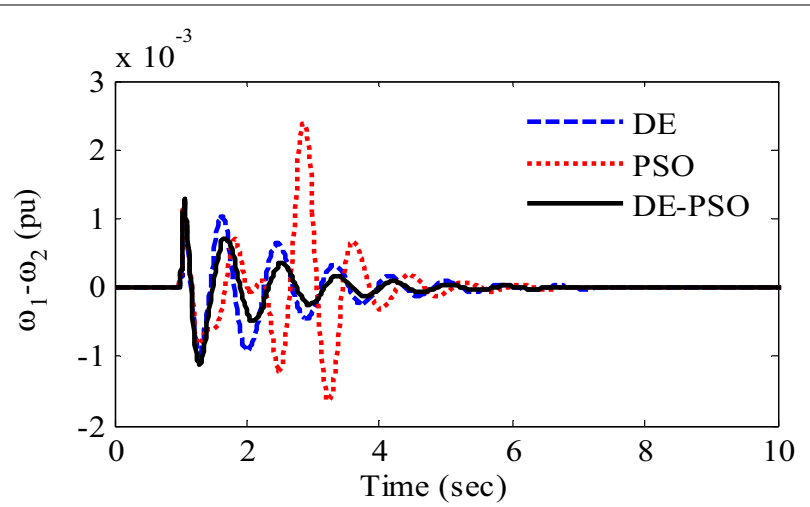

Fig. 3 Local mode oscillation

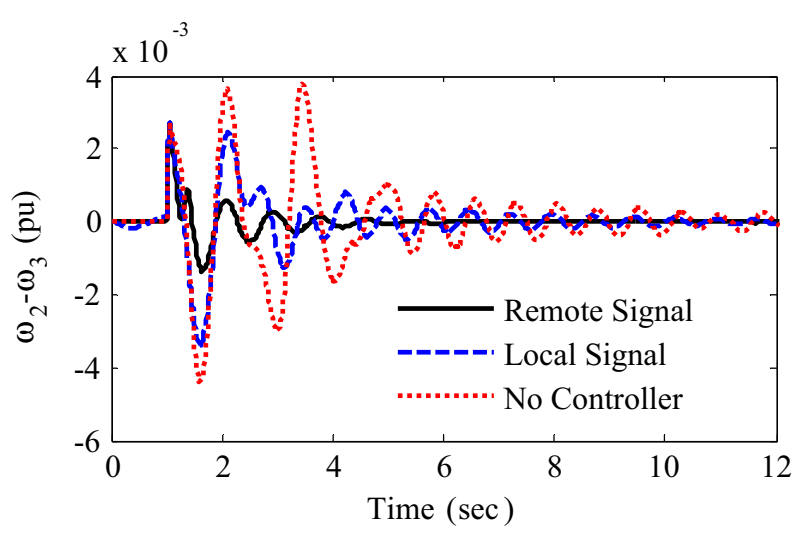

Fig. 4 Inter-area mode oscillation

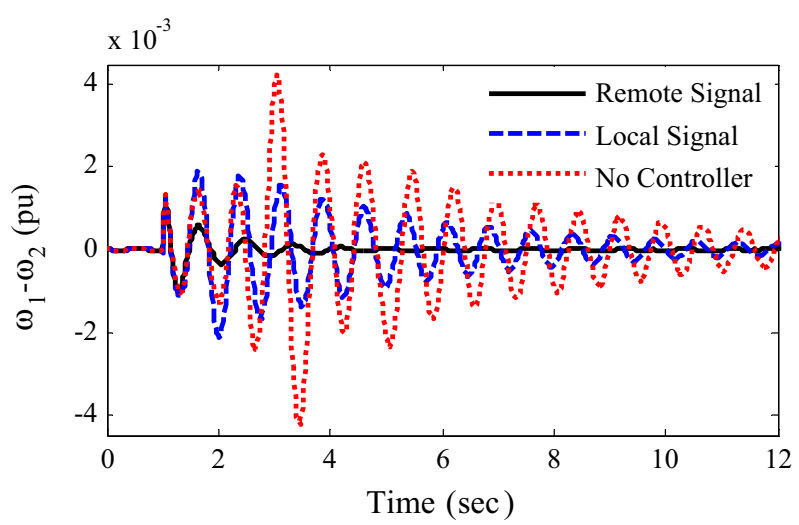

Fig. 5 Local mode oscillation

remote signal. The response of the system with no controller is shown with dotted line (with legend $\mathrm{NC}$ ); response with local signal is shown with dashed line (with legend local signal); and response with remote signal is shown with solid line (with 


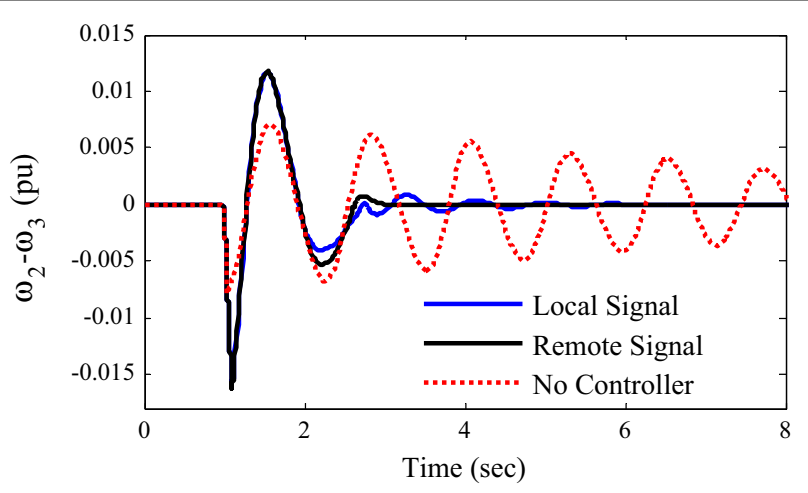

Fig. 6 Inter-area mode oscillation

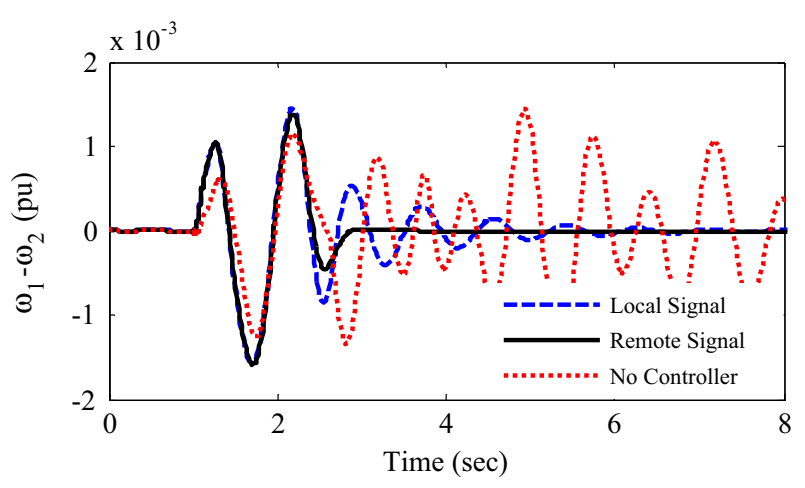

Fig. 7 Local mode oscillation

legend remote signal). These results show that the remote signal is the best option as the control input for the controller than the local signal.

Case 2 Load rejection: Then, a disturbance as load rejection has been considered by taking out the load at bus- 3 at $t=1 \mathrm{~s}$ for a period of $100 \mathrm{~ms}$. Figures 6 and 7 show the system response for inter-area and local mode of oscillations, respectively. From the figures, we can observe that the proposed controller using remote signal is a better choice for effective damping power system oscillations.

Case 3 Tripping of one parallel transmission line: At last, the case of tripping off of parallel lines has been considered. First, half of one parallel line is tripped off for a period of $100 \mathrm{~ms}$ at $t=1 \mathrm{~s}$. Then, one full parallel line is tripped off at $t=1 \mathrm{~s}$ for $100 \mathrm{~ms}$ and finally one parallel line is tripped off at $t=1 \mathrm{~s}$ for a period of $187 \mathrm{~ms}$. Figure 8 shows the system response for inter-area mode of oscillations for the above disturbance conditions. Figures 4, 5, 6, 7 and 8 clearly indicate that the proposed approach can damp out these oscillations efficiently compared to without controller (no controller). 

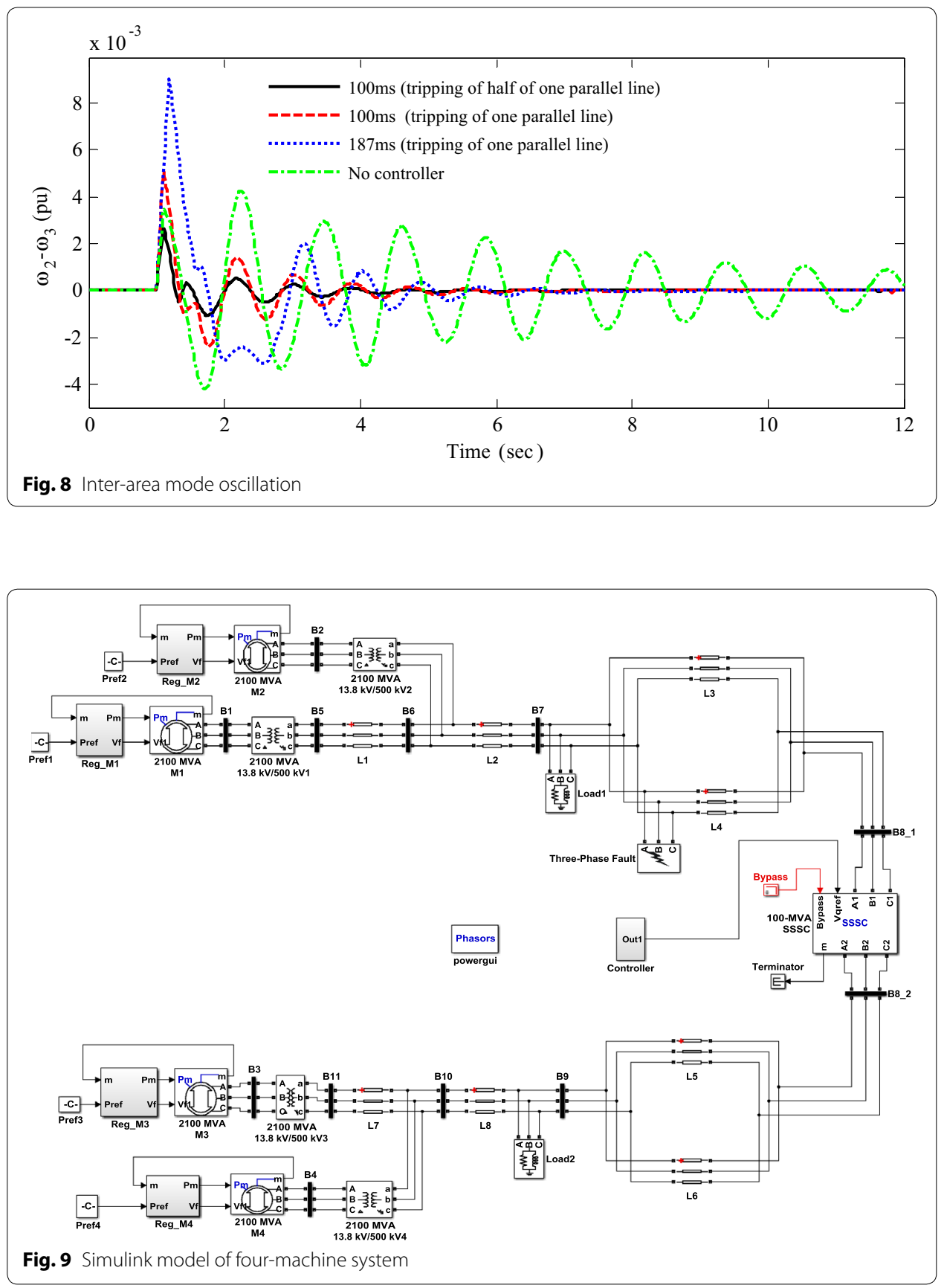

\section{Extension to four-machine system}

Figure 9 shows the MATLAB/SIMULINK model of the four-machine power system. The load flow and machine initialization parameters are given in Table 3. The optimized values of the controller parameters are provided in Table 4.

Case 1 Three-phase to ground fault

A five-cycle three-phase fault is applied at bus-7, at $t=1 \mathrm{~s}$. The fault is cleared by the tripping of the faulted line. The line is reclosed after five cycles, and the original system is restored. The system response under this severe fault is shown in Figs. 10, 11, 12 
Table 3 Load flow and machine initialization

\begin{tabular}{|c|c|c|c|c|}
\hline Machine name & Generator $1 \mathrm{M} 1$ & Generator $2 \mathrm{M} 2$ & Generator 3 M3 & Generator 4 M4 \\
\hline Nominal values & 2100 MVA 13.8 kV rms & 2100 MVA 13.8 kV rms & $\begin{array}{l}2100 \mathrm{MVA} 13.8 \mathrm{kV} \\
\text { rms }\end{array}$ & $2100 \mathrm{MVA} 13.8 \mathrm{kV}$ rms \\
\hline Bus type & Swing bus & $P$ and $V$ generator & P and Q generator & $\mathrm{P}$ and $\mathrm{Q}$ generator \\
\hline Uan phase & $-0.00^{\circ}$ & $-2.19^{\circ}$ & $-18.27^{\circ}$ & $-22.60^{\circ}$ \\
\hline Uab & $\begin{array}{l}13,800 \text { Vrms [1 pu] } \\
30.00^{\circ}\end{array}$ & $\begin{array}{l}13,800 \mathrm{Vrms}[1 \mathrm{pu}] \\
27.81^{\circ}\end{array}$ & $\begin{array}{l}16,060 \text { Vrms }[1.164 \\
\mathrm{pu}] 11.73^{\circ}\end{array}$ & $\begin{array}{l}15,853 \text { Vrms [1.149 pu] } \\
7.40^{\circ}\end{array}$ \\
\hline Ubc & $\begin{array}{l}13,800 \mathrm{Vrms}[1 \mathrm{pu}] \\
-90.00^{\circ}\end{array}$ & $\begin{array}{l}13,800 \text { Vrms [1 pu] } \\
-92.19^{\circ}\end{array}$ & $\begin{array}{c}16,060 \text { Vrms }[1.164 \\
\mathrm{pu}]-108.27^{\circ}\end{array}$ & $\begin{array}{l}15,853 \text { Vrms }[1.149 \mathrm{pu}] \\
\quad-112.60^{\circ}\end{array}$ \\
\hline Uca & $\begin{array}{l}13,800 \text { Vrms [1 pu }] \\
150.00^{\circ}\end{array}$ & $\begin{array}{l}13,800 \text { Vrms [1 pu] } \\
147.81^{\circ}\end{array}$ & $\begin{array}{l}16,060 \text { Vrms }[1.164 \\
\mathrm{pu}] 131.73^{\circ}\end{array}$ & $\begin{array}{l}15,853 \mathrm{Vrms}[1.149 \mathrm{pu}] \\
127.40^{\circ}\end{array}$ \\
\hline la & $\begin{array}{l}42,268 \text { Arms [0.4811 } \\
\text { pu] } 4.21^{\circ}\end{array}$ & $\begin{array}{l}66,026 \text { Arms }[0.7515 \\
\text { pu] } 4.38^{\circ}\end{array}$ & $\begin{array}{l}57,809 \text { Arms }[0.658 \\
\mathrm{pu}]-29.62^{\circ}\end{array}$ & $\begin{array}{l}64,160 \text { Arms [0.7303 } \\
\mathrm{pu}]-32.60^{\circ}\end{array}$ \\
\hline $\mathrm{lb}$ & $\begin{array}{l}42,268 \text { Arms }[0.4811 \\
\mathrm{pu}]-115.79^{\circ}\end{array}$ & $\begin{array}{c}66,026 \text { Arms }[0.7515 \\
\mathrm{pu}]-115.62^{\circ}\end{array}$ & $\begin{array}{l}\text { 57,809 Arms [0.658 } \\
\mathrm{pu}]-149.62^{\circ}\end{array}$ & $\begin{array}{l}64,160 \text { Arms }[0.7303 \\
\mathrm{pu}]-152.60^{\circ}\end{array}$ \\
\hline IC & $\begin{array}{l}\text { 42,268 Arms [0.4811 } \\
\text { pu] } 124.21^{\circ}\end{array}$ & $\begin{array}{l}66,026 \text { Arms [0.7515 } \\
\text { pu] } 124.38^{\circ}\end{array}$ & $\begin{array}{l}\text { 57,809 Arms [0.658 } \\
\text { pu] } 90.38^{\circ}\end{array}$ & $\begin{array}{l}64,160 \text { Arms [0.7303 } \\
\text { pu] } 87.40^{\circ}\end{array}$ \\
\hline P & $\begin{array}{l}1.0076 \mathrm{e}+009 \mathrm{~W} \\
{[0.4798 \mathrm{pu}]}\end{array}$ & $\begin{array}{c}1.5678 \mathrm{e}+009 \mathrm{~W} \\
{[0.7466 \mathrm{pu}]}\end{array}$ & $\begin{array}{l}1.5766 \mathrm{e}+009 \mathrm{~W} \\
{[0.7508 \mathrm{pu}]}\end{array}$ & $\begin{array}{l}1.735 \mathrm{e}+009 \mathrm{~W}[0.8262 \\
\mathrm{pu}]\end{array}$ \\
\hline Q & $\begin{array}{c}-7.4234 \mathrm{e}+007 \text { Vars } \\
{[-0.03,535 \mathrm{pu}]}\end{array}$ & $\begin{array}{c}-1.8057 \mathrm{e}+008 \text { Vars } \\
{[-0.08598 \mathrm{pu}]}\end{array}$ & $\begin{array}{l}\text { 3.1651e+008 Vars } \\
{[0.1507 \mathrm{pu}]}\end{array}$ & $\begin{array}{c}3.0588 \mathrm{e}+008 \text { Vars } \\
{[0.1457 \mathrm{pu}]}\end{array}$ \\
\hline Pmec & $\begin{array}{c}1.009 \mathrm{e}+009 \mathrm{~W} \\
{[0.4805 \mathrm{pu}]}\end{array}$ & $\begin{array}{c}1.5712 \mathrm{e}+009 \mathrm{~W} \\
{[0.7482 \mathrm{pu}]}\end{array}$ & $\begin{array}{l}1.5792 \mathrm{e}+009 \mathrm{~W} \\
{[0.752 \mathrm{pu}]}\end{array}$ & $\begin{array}{c}1.7382 \mathrm{e}+009 \mathrm{~W} \\
{[0.8277 \mathrm{pu}]}\end{array}$ \\
\hline Torque & $\begin{array}{c}8.5644 \mathrm{e}+007 \mathrm{~N} \mathrm{~m} \\
{[0.4805 \mathrm{pu}]}\end{array}$ & $\begin{array}{c}1.3337 \mathrm{e}+008 \mathrm{~N} \mathrm{~m} \\
{[0.7482 \mathrm{pu}]}\end{array}$ & $\begin{array}{l}1.3405 \mathrm{e}+008 \mathrm{~N} \mathrm{~m} \\
{[0.752 \mathrm{pu}]}\end{array}$ & $\begin{array}{c}1.4754 \mathrm{e}+008 \mathrm{~N} \mathrm{~m} \\
{[0.8277 \mathrm{pu}]}\end{array}$ \\
\hline Vf & $1.0717 \mathrm{pu}$ & $1.1719 \mathrm{pu}$ & $1.4984 \mathrm{pu}$ & $1.5211 \mathrm{pu}$ \\
\hline
\end{tabular}

Table 4 Optimized controller parameters

\begin{tabular}{lllllll}
\hline Techniques & $K_{s}$ & $T_{1 \mathbf{s}}$ & $T_{2 s}$ & $T_{3 \mathbf{s}}$ & $T_{4 s}$ & ITAE \\
\hline hDE-PSO & 260.6834 & 0.0540 & 0.1592 & 0.7792 & 0.2802 & 0.0011
\end{tabular}

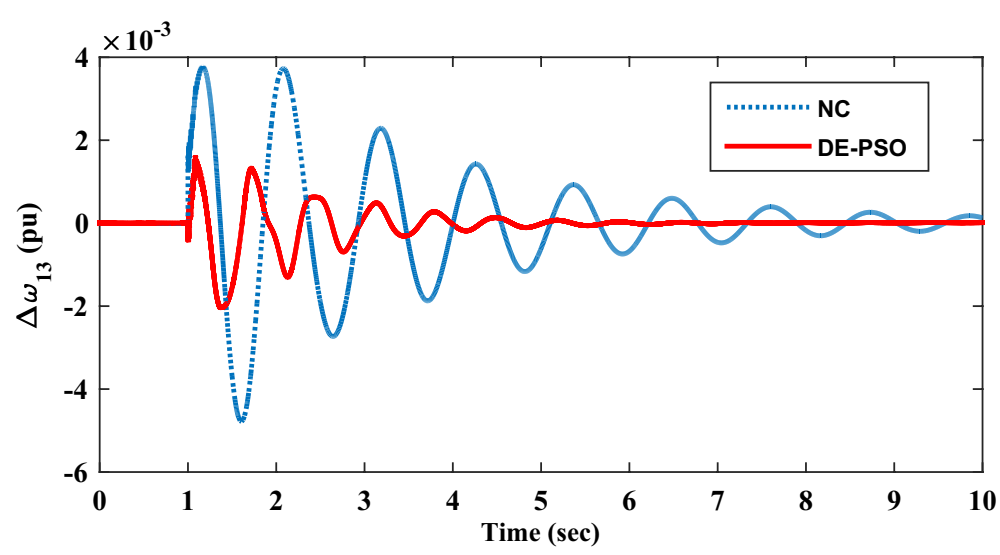

Fig. 10 Inter-area mode oscillation between machines 1 and 3

and 13. Figure 10 shows the response of speed deviation of inter-area mode of oscillation between machines 1 and 3, Fig. 11 shows the response of speed deviation of interarea mode of oscillation between machines 1 and 4, Fig. 12 shows the response of speed 


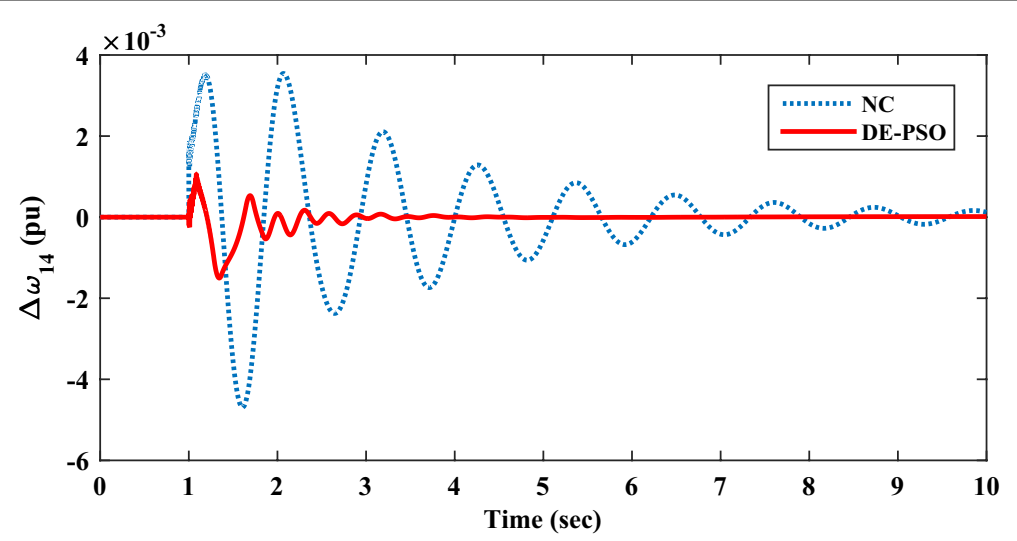

Fig. 11 Inter-area mode oscillation between machines 1 and 4

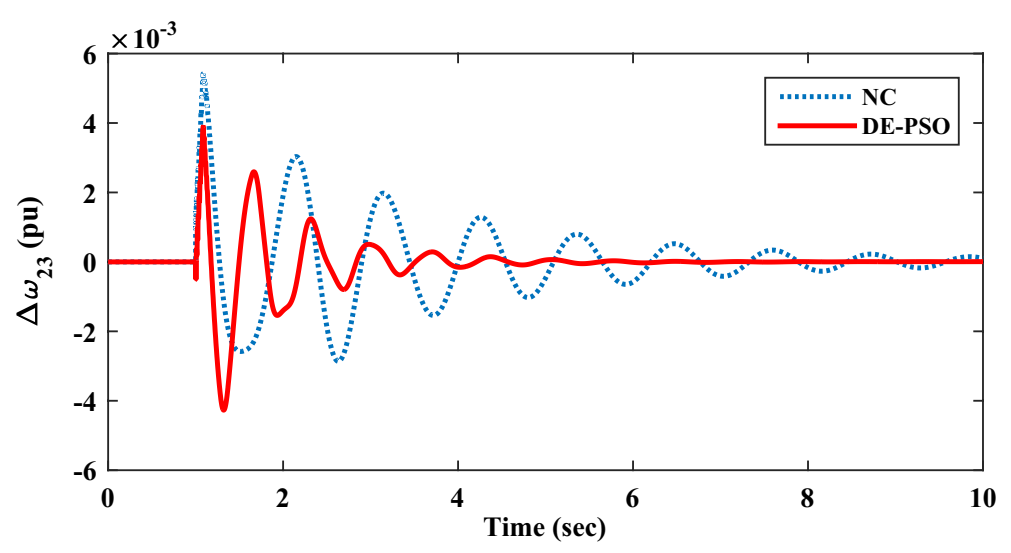

Fig. 12 Inter area mode oscillation between machine 2 and 3

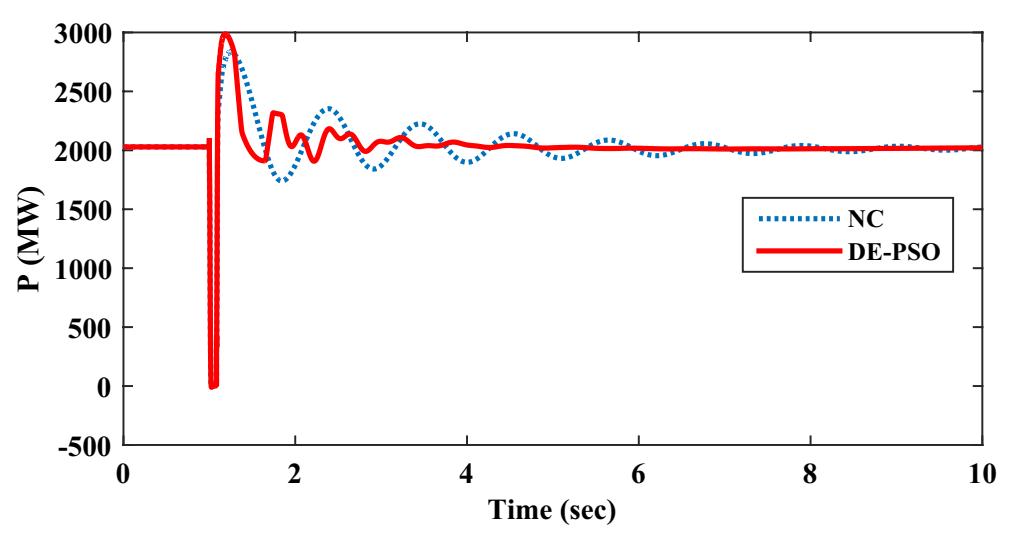

Fig. 13 Tie-line power at bus-7

deviation of inter-area mode of oscillation between machines 2 and 3, and Fig. 13 shows the response of tie-line power. In those figures, the response with a hybrid DE-PSObased controller is shown with solid red line (with legend DE-PSO) and that without 


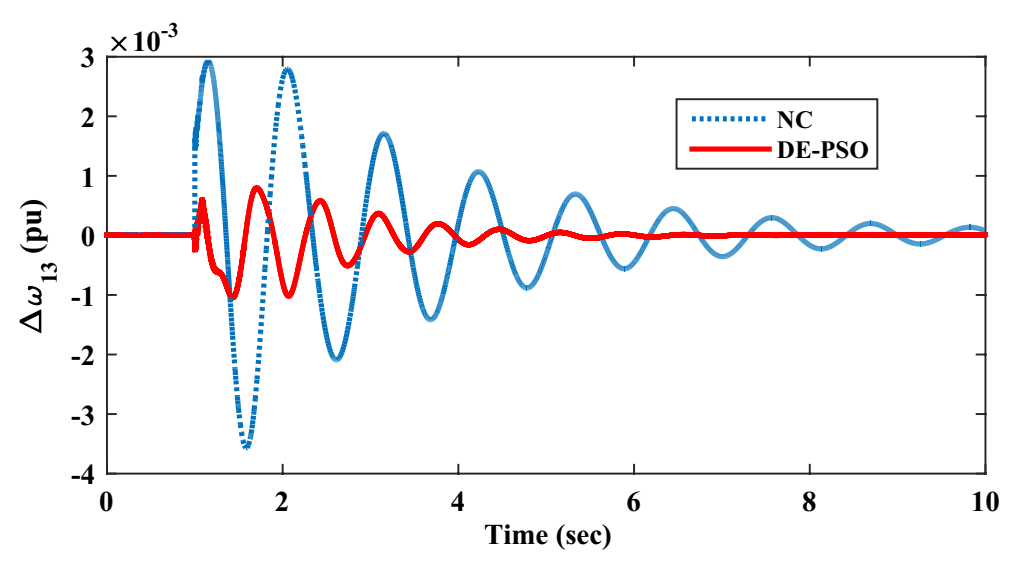

Fig. 14 Inter-area mode oscillation between machines 1 and 3

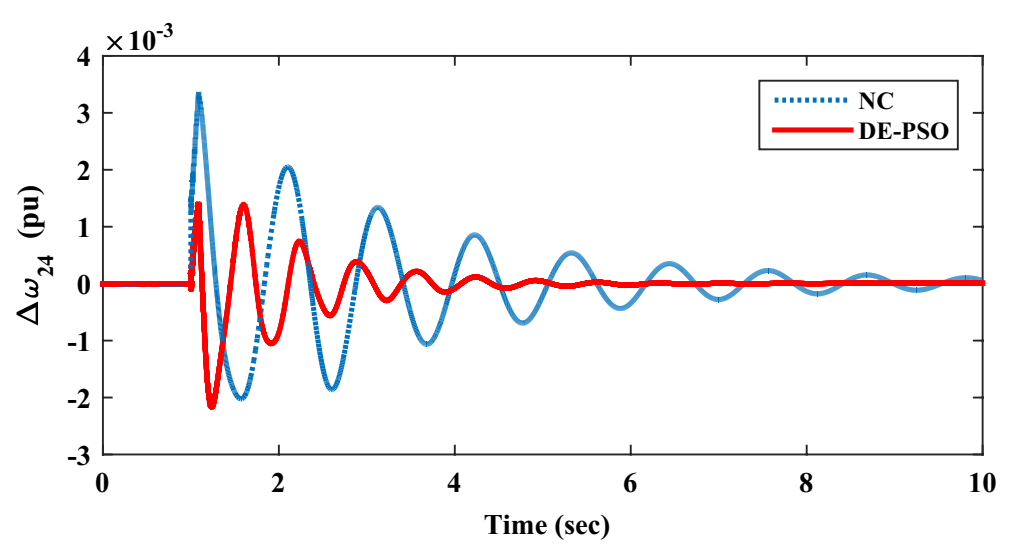

Fig. 15 Inter-area mode oscillation between machines 2 and 4

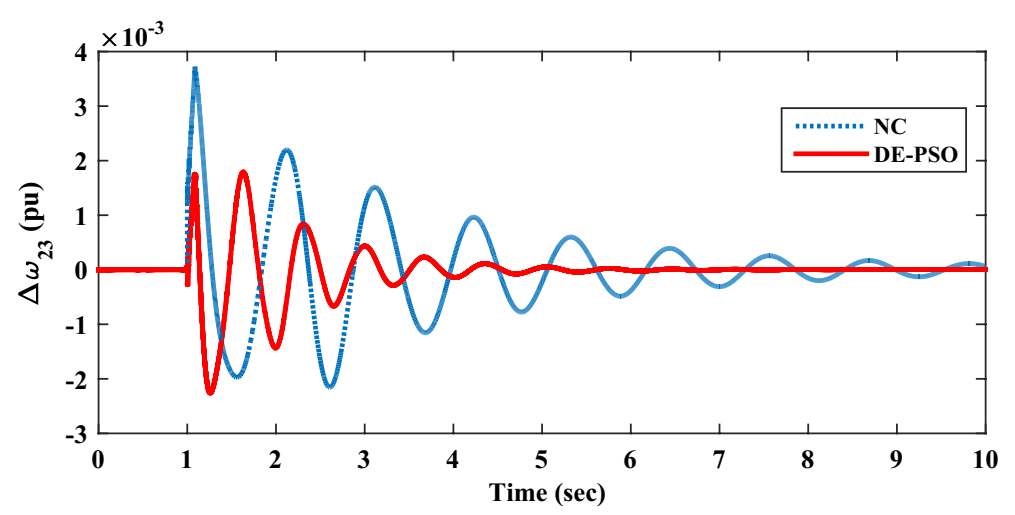

Fig. 16 Inter-area mode oscillation between machines 2 and 3

controller is shown with dashed blue line (with legend NC). From these figures, it is clear that the proposed controller gives a better response in terms of damping and settling time. 


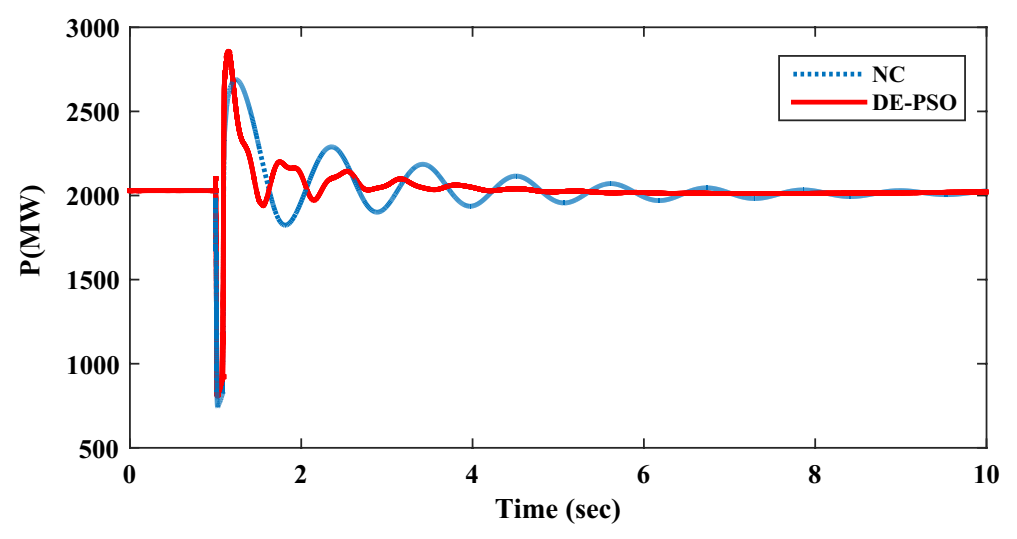

Fig. 17 Tie-line power at bus-7

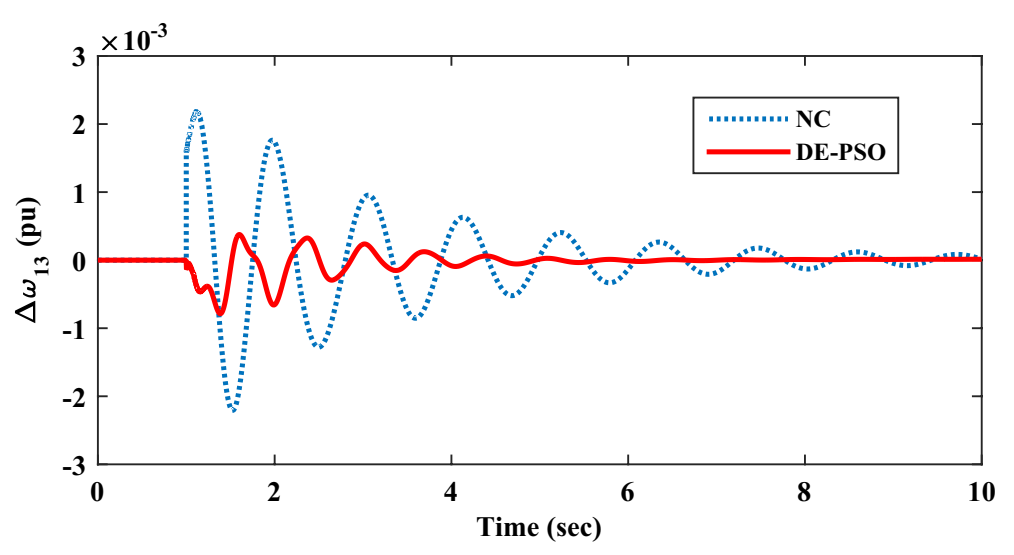

Fig. 18 Inter-area mode oscillation between machines 1 and 3

Case 2 Double-line to ground fault

A five-cycle double-line to ground (LLG) fault is applied at bus-7, at $t=1 \mathrm{~s}$. The fault is cleared by the tripping of the faulted line. The line is reclosed after five cycles, and the original system is restored. The system response under this severe fault is shown in Figs. 14, 15, 16 and 17. Figure 14 shows the response of speed deviation of inter-area mode of oscillation between machines 1 and 3, Fig. 15 shows the response of speed deviation of inter-area mode of oscillation between machines 2 and 4, Fig. 16 shows the response of speed deviation of inter-area mode of oscillation between machines 2 and 3, and Fig. 17 shows the response of tie-line power. In those figures, the response with hybrid DE-PSO-based controller is shown with solid red line (with legend DE-PSO) and that without controller is shown with dashed blue line (with legend NC). From Figs. 14, 15,16 and 17, it is clear that the proposed controller gives a better response in terms of damping and settling time.

Case 3 Single-line to ground fault

A five-cycle single-line to ground (LG) fault is applied at bus-7, at $t=1 \mathrm{~s}$. The fault is cleared by the tripping of the faulted line. The line is reclosed after five cycles, and the original system is restored. The system response under this severe fault condition is shown in Figs. 18, 19, 20, 21 and 22. Figure 18 shows the response of speed deviation 


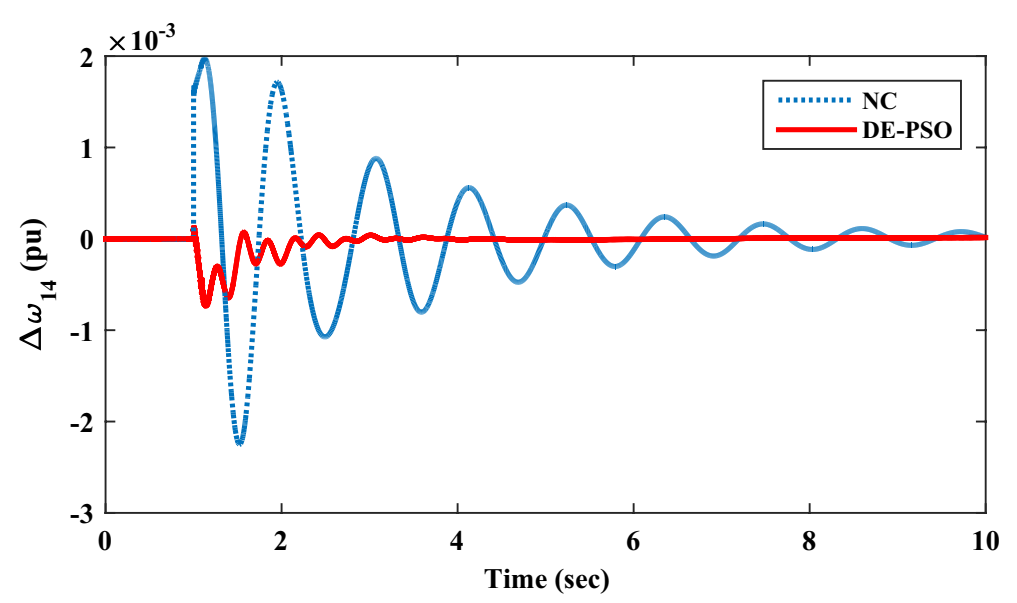

Fig. 19 Inter-area mode oscillation between machines 1 and 4

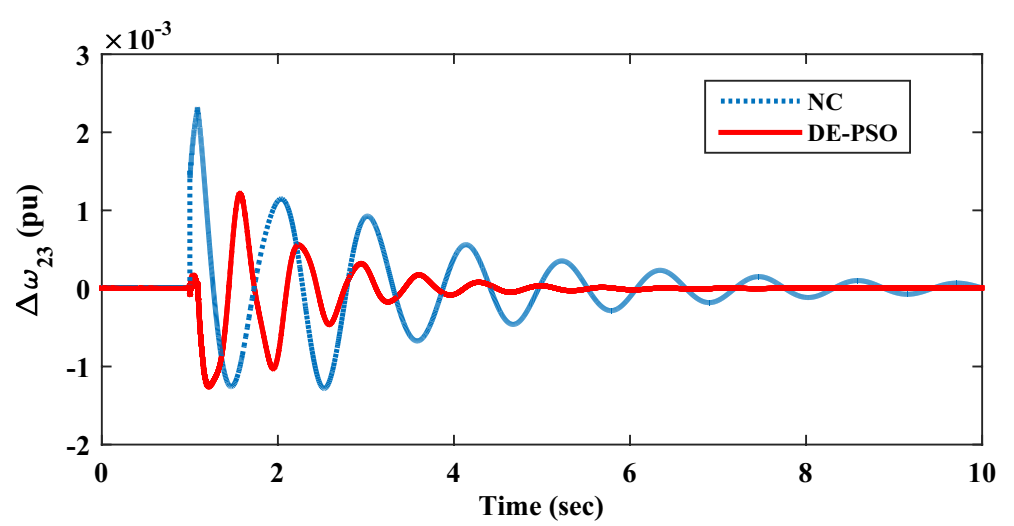

Fig. 20 Inter-area mode oscillation between machines 2 and 3

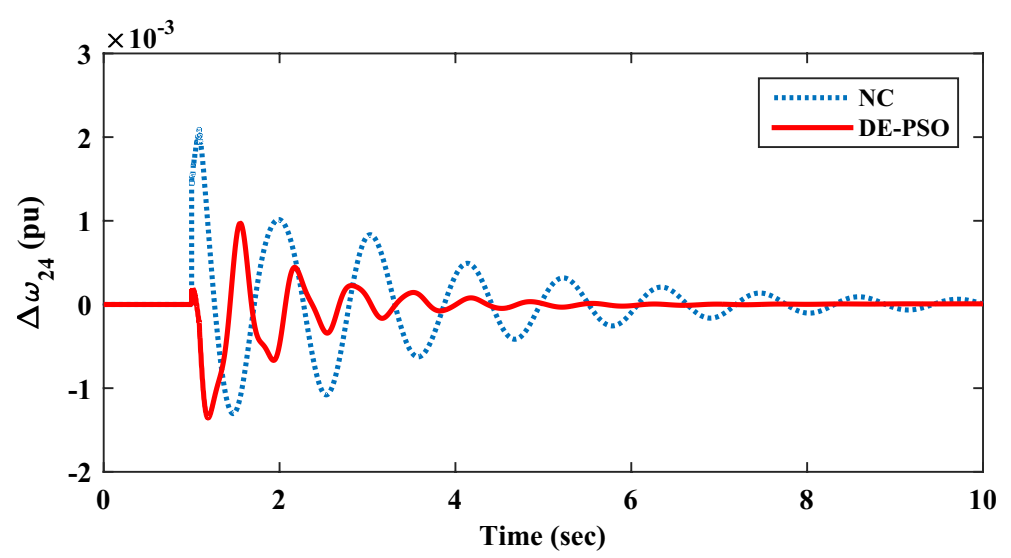

Fig. 21 Inter-area mode oscillation between machines 2 and 4 


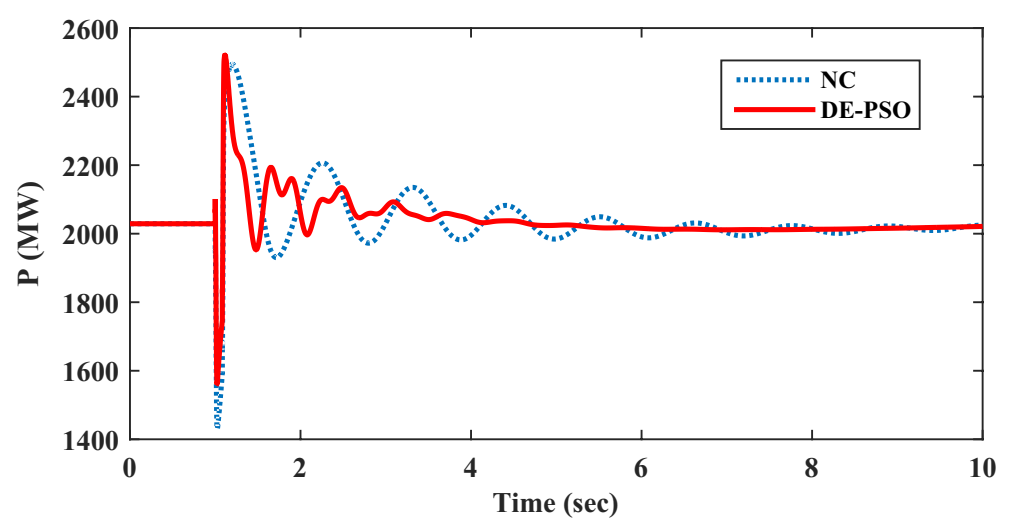

Fig. 22 Tie-line power at bus-7

of inter-area mode of oscillation between machines 1 and 3, Fig. 19 shows the response of speed deviation of inter-area mode of oscillation between machines 1 and 4, Fig. 20 shows the response of speed deviation of inter-area mode of oscillation between machines 2 and 3, Fig. 21 shows the response of speed deviation of inter-area mode of oscillation between machines 2 and 4, and Fig. 22 shows the response of tie-line power. In those figures, the response with hybrid DE-PSO-based controller is shown with solid red line (with legend DE-PSO) and that without controller is shown with dashed blue line (with legend NC). From Figs. 18, 19, 20, 21 and 22, it is clear that the proposed controller gives a better response in terms of damping and settling time.

\section{Conclusion}

In this paper, a study has been carried out for the improvement in the power system stability by damping of power system oscillations. The SSSC-based controller (lead-lag structure) is used for damping out of power system oscillations. The controller parameters are tuned using the hDE-PSO algorithm. The simulation results are compared with the results obtained from tuning the controller parameters using DE and PSO to show the effectiveness and robustness of the proposed controller. Also, the effectiveness of the controller is checked using different kinds of disturbances. The analysis infers that the proposed controller structure can be implemented in power system for stability enhancement.

\section{Acknowledgements}

We are thankful to the Department of Electrical Engineering, Veer Surendra Sai University of Technology, Burla, Odisha, India 768018.

\section{Authors' contributions}

The authors SB, AKB, ND and DKL have read and approved the manuscript. All authors have contributed to this accepted manuscript.

\section{Funding}

This study had no funding from any resource.

Availability of data and materials

Availability of data and materials are cited in references of the manuscript.

\section{Competing interests}

The authors declare that they have no competing interests.

\section{Author details}

${ }^{1}$ Department of Electrical Engineering, Veer Surendra Sai University of Technology, Burla, Odisha 768018, India. ${ }^{2}$ Department of Electrical Engineering, College of Engineering and Technology, Bhubaneswar, Odisha 751029, India. ${ }^{3}$ Department of Electrical Engineering, Indian Institute of Technology, Kharagpur, Kharagpur, West Bengal 721302, India. ${ }^{4}$ Department of Electrical Engineering, Government College of Engineering, Bhawanipatna, Kalahandi, Odisha 766002, India. 


\section{Appendix: Four machines}

(1) Generator

$S_{B 1}=S_{B 2}=S_{B 3}=S_{B 4}=2100 \quad$ MVA $, \quad H=3.7 \quad \mathrm{~s}, \quad V_{B}=13.8 \quad \mathrm{kV}, \quad f=60 \quad \mathrm{~Hz}$, $R_{S}=2.8544 \mathrm{e}-3, X_{d}=1.305, X_{d}^{\prime}=0.296, X_{d}^{\prime \prime}=0.252, X_{q}=0.474, X_{q}^{\prime}=0.243, X_{q}^{\prime \prime}=0.18$, $T_{d}=1.01 \mathrm{~s}, T_{d}^{\prime}=1.01 \mathrm{~s}, T_{q 0}^{\prime \prime}=0.1 \mathrm{~s}$.

(2) Loads

Load1 $=1167 \mathrm{MW}+100$ MVAR, Load2 =3617.5 MW + 100MVAR.

(3) Hydraulic turbine and governor

$K_{a}=3.33, T_{a}=0.07, G_{\min }=0.01, G_{\max }=0.97518, V_{g \min }=-0.1 \mathrm{pu} / \mathrm{s}, V_{g \max }=0.1 \mathrm{pu} / \mathrm{s}$, $R_{p}=0.05, K_{p}=1.163, K_{i}=0.105, K_{d}=0, T_{d}=0.01 \mathrm{~s}, \beta=0, T_{w}=2.67 \mathrm{~s}$.

(4) Excitation system

$\mathrm{TLP}=0.02 \mathrm{~s}, K_{a}=200, T_{a}=0.001 \mathrm{~s}, K_{e}=1, T_{e}=0, T_{b}=0, T_{c}=0, K_{f}=0.001, T_{f}=0.1 \mathrm{~s}$, $E_{f \min }=0, E_{f \min }=7, K_{p}=0$.

(5) Transformer

$S_{B T 1}=S_{B T 2}=S_{B T 3}=S_{B T 4}=2100 \mathrm{MVA}, S_{B T 3}=4200 \mathrm{MVA}, 13.8 / 500 \mathrm{kV}, f=60 \mathrm{~Hz}$, $R_{1}=R_{2}=0.002, L_{1}=0, L_{2}=0.12, D_{1} / Y_{g}$ connection, $R_{m}=500, L_{m}=500$.

(6) Transmission line

$3-\mathrm{Ph}, 60 \mathrm{~Hz}, L_{1}=50 \mathrm{~km}, L_{2}=20 \mathrm{~km}, L_{3}=220 \mathrm{~km}, R_{1}=0.02546 \Omega / \mathrm{km}, R_{0}=0.3864 \Omega /$ $\mathrm{km}, L_{m}=0.9337 \mathrm{e}-3 \mathrm{H} / \mathrm{km}, L_{0}=4.1264 \mathrm{e}-3 \mathrm{H} / \mathrm{km}, C_{1}=12.74 \mathrm{e}-9 \mathrm{~F} / \mathrm{km}, C_{0}=7.751 \mathrm{e}-9$ $\mathrm{F} / \mathrm{km}$.

(7) SSSC

$S_{\text {nom }}=100 \mathrm{MVA}, V_{\text {nom }}=500 \mathrm{kV}, f=60 \mathrm{~Hz}, V_{q \max }=0.2$, Max rate of change of $V_{\text {qref }}=3$ $\mathrm{pu} / \mathrm{s}, R_{\mathrm{cnv}}=0.00533, L_{\mathrm{cnv}}=0.16, V_{\mathrm{DC}}=40 \mathrm{kV}, C_{\mathrm{DC}}=75 \mathrm{e}-6 \mathrm{~F}, \mathrm{KP} \_\mathrm{IVR}=0.00375, \mathrm{KI}$ $\mathrm{IVR}=0.1875, \mathrm{KP}_{-} \mathrm{VdcR}=0.1 \mathrm{e}-3, \mathrm{KP} \_\mathrm{VdcR}=20 \mathrm{e}-3$.

Received: 24 September 2019 Accepted: 12 November 2019

Published online: 19 December 2019

\section{References}

1. Kundur P (1994) Power system stability and control. Mc-Grall Hill, New York

2. Pal B, Chaudhuri B (2005) Robust control in power systems. Springer, Berlin

3. Hingorani NG, Gyugyi L (2000) Understanding FACTS: concepts and technology of flexible AC transmission systems. IEEE Press, New York 
4. Panda S, Padhy N, Patel R (2007) Modelling, simulation and optimal tuning of TCSC controller. Int J Simul Model 6(1):37-48

5. Naderi Y, Rahimi T, Yousefi B, Hosseini SH (2014) Assessment power and frequency oscillation damping using POD controller and proposed FOD Controller. WASET Int J Electr Comput Energ Electron Commun Eng 8(1 1):1801-1807

6. Gyugyi L, Schauder CD, Sen KK (1997) Static synchronous series compensator: a solid-state approach to the series compensation of transmission lines. IEEE Trans Power Deliv 12:406-417

7. Sen KK (1998) SSSC-static synchronous series compensator: theory, modelling and applications. IEEE Trans Power Deliv 13:241-246

8. Wang HF (2000) Static synchronous series compensator to damp power system oscillations. Electr Power Syst Res 54:113-119

9. Menniti D, Pinnarelli A, Scordino N, Sorrentino N (2004) Using a FACTS device controlled by a decentralised control law to damp the transient frequency deviation in a deregulated electric power system. Electr Power Syst Res 72:289-298

10. Al Jowder FAR (2005) Influence of mode of operation of the SSSC on the small disturbance and transient stability of a radial power system. IEEE Trans Power Syst 20(2):935-942

11. Udhayashankar C, Zachariah P, Thottungal R, Nithyadevi N (2012) SSSC based voltage control and power oscillation damping of multi-area power system. Eur J Sci Res 87(4):479-490

12. Aboul-Ela ME, Salam AA, McCalley JD, Fouad AA (1996) Damping controller design for power system oscillations using global signals. IEEE Trans Power Syst 11(2):767-773

13. Panda S, Swain SC, Rautray PK, Mallik R, Panda G (2010) Design and analysis of SSSC based supplementary damping controller. Simul Model Pract Theory 18:1199-1213

14. Panda S (2011) Differential evolution algorithm for SSSC based damping controller design considering time delay. J Frankl Inst 348:1903-1926

15. Panda S, Padhy NP, Patel RN (2008) Power system stability improvement by PSO optimized SSSC-based damping controller. Electric Power Compon Syst 36(5):468-490

16. Sahu BK, Pati S, Panda S (2014) Hybrid differential evolution particle swarm optimisation optimised fuzzy proportional-integral derivative controller for automatic generation control of interconnected power system. IET Gener Transm Distrib 8(11):1789-1800

\section{Publisher's Note}

Springer Nature remains neutral with regard to jurisdictional claims in published maps and institutional affiliations.

\section{Submit your manuscript to a SpringerOpen ${ }^{\circ}$ journal and benefit from:}

- Convenient online submission

Rigorous peer review

- Open access: articles freely available online

- High visibility within the field

- Retaining the copyright to your article

Submit your next manuscript at $\gg$ springeropen.com 